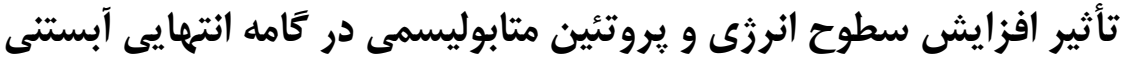 بر رشد و تكامل يستان بز هاى سيستانى
}

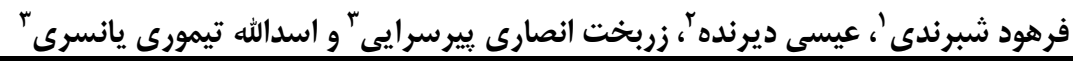

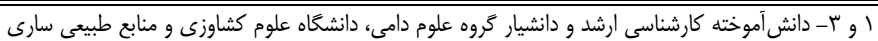

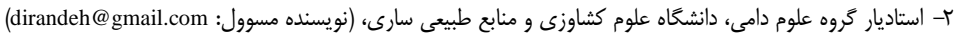

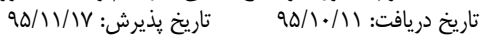

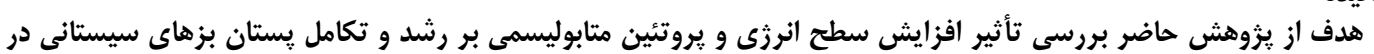

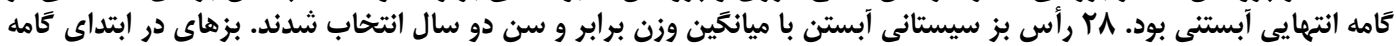

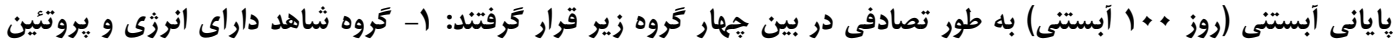

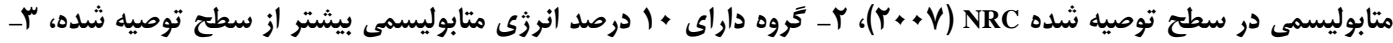

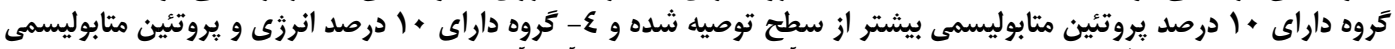

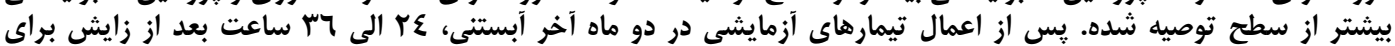

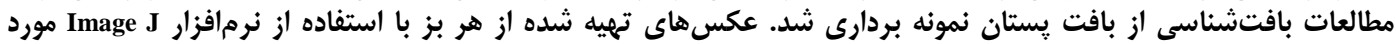

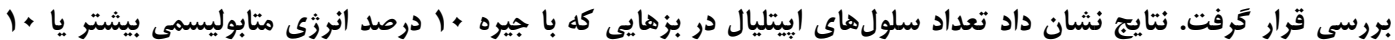

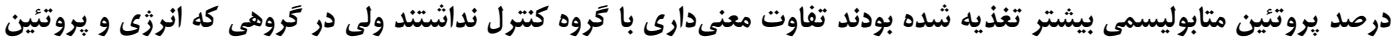

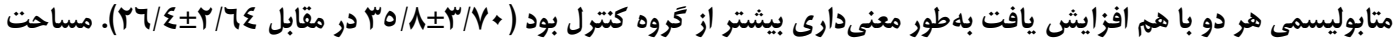

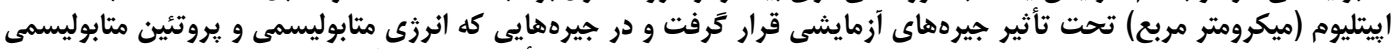

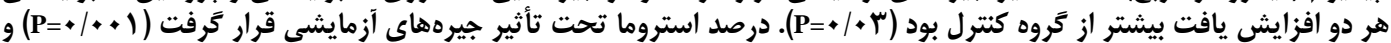

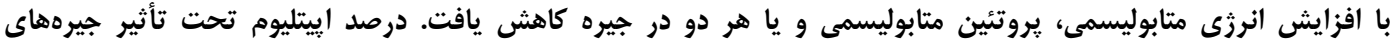

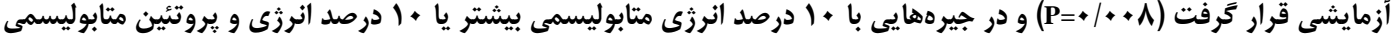

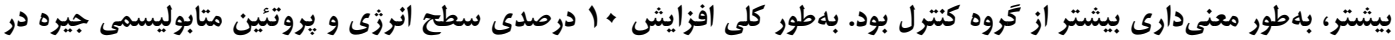

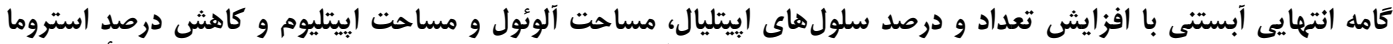

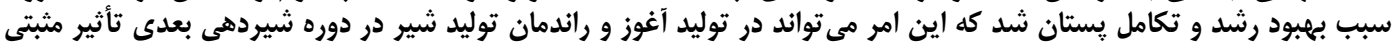

داشته باشد.

وازههاى كليدى: آلوئول، انرزى متابوليسمى، بافت يستان، بز سيستانى، سلول إيتيليال

ناكافى خوراك طى اواخر آبستنى ممكن است وزن تولن تولد،

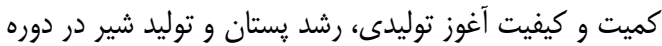

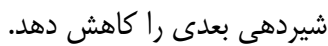

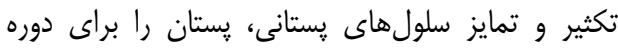

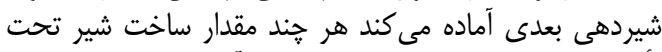

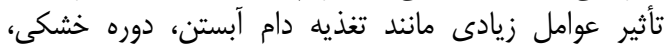

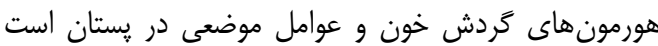

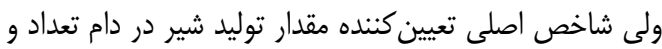

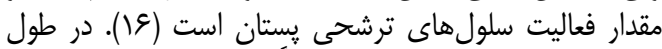

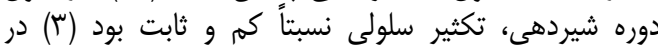

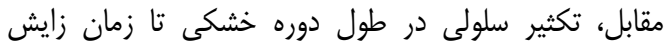

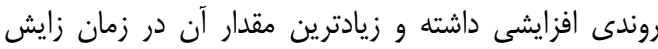

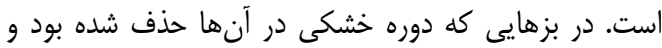

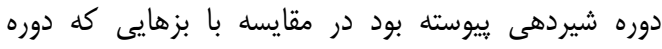

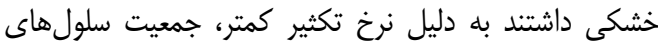

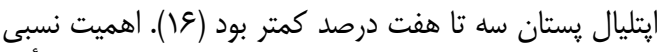

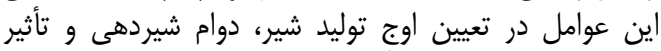

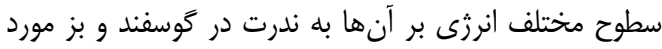

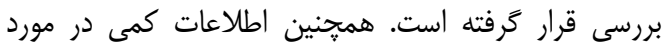

تغذيه در دوران آبستنى هم بلهطور مستقيم از راه تأمين أنغين

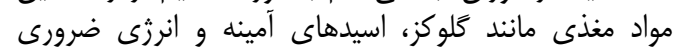

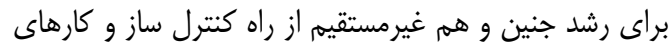

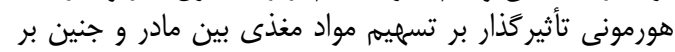

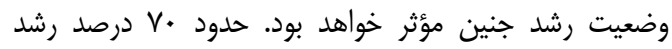

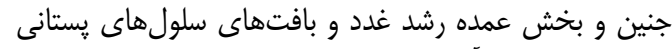

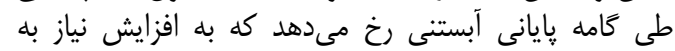

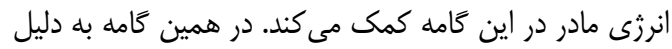



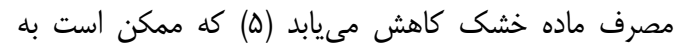

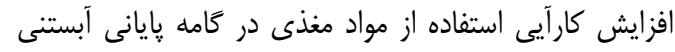

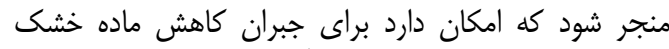

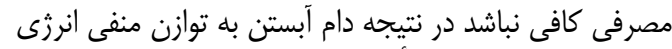

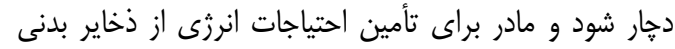

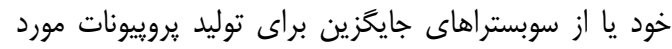

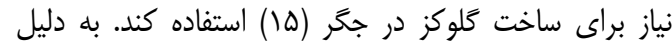

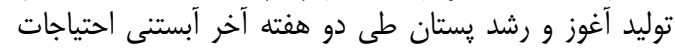






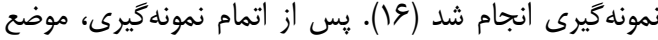

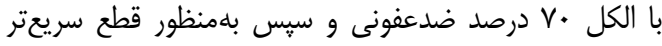

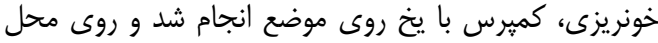

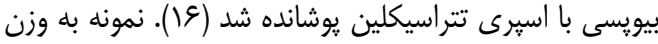

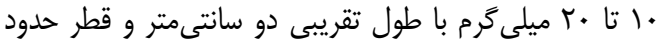

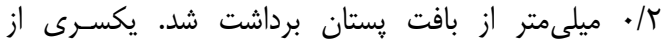

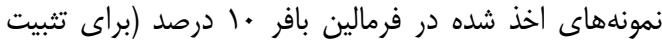

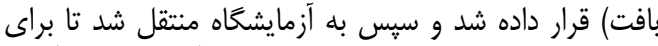

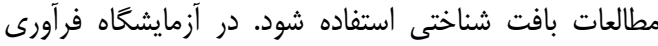

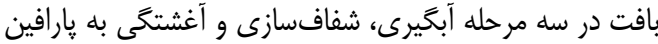

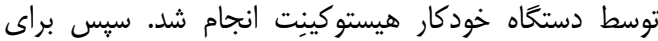

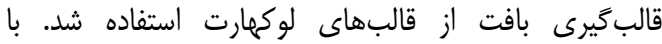

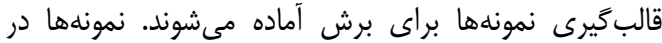

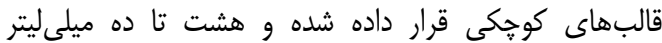

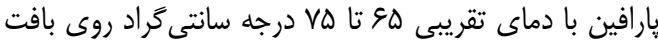

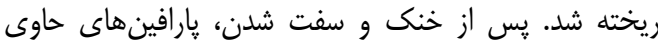

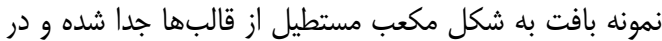

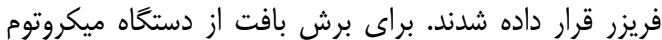

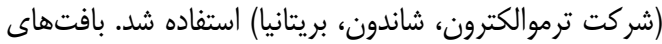

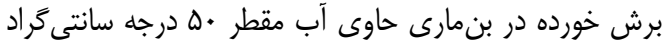

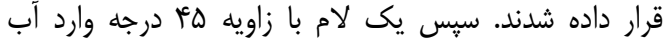

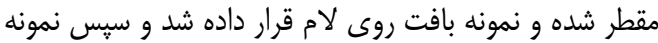

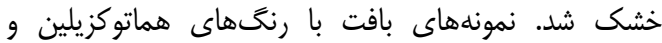

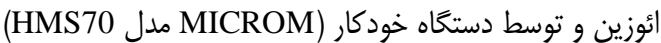

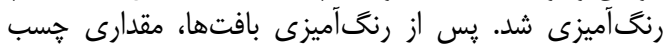

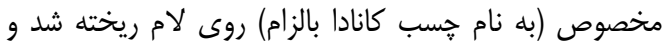

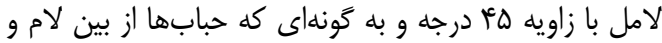

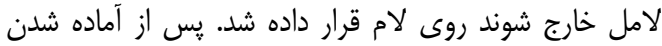

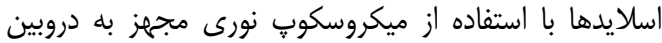

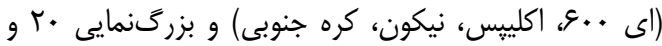

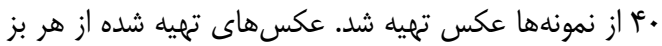

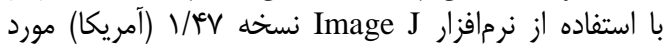

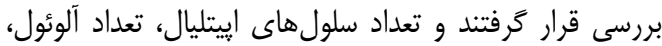

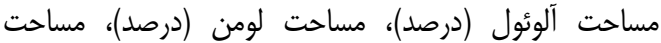

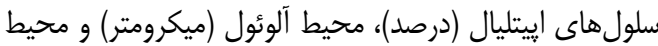

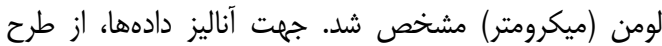



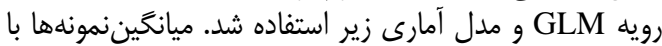




$Y_{i j}=\mu+A_{i}+e_{i j}$

$$
\begin{aligned}
& \text { = اندازه هر مشاهده از آزمايش =Y } \\
& \text { = } \\
& \text { = اثر تيمارهاى مختلف = A }
\end{aligned}
$$

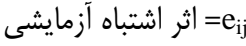

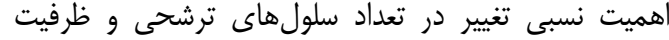



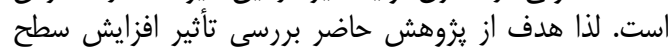


و تكامل يستان بز سيستانى بود.

\section{مواد و روشها}

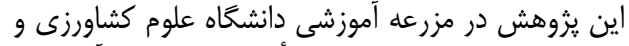



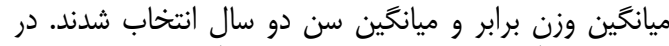

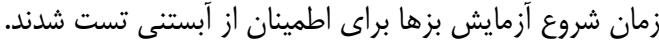

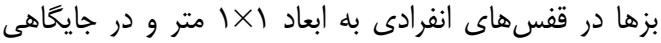







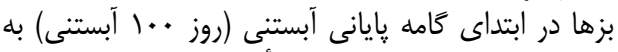

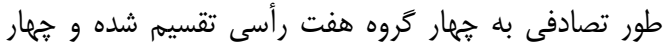

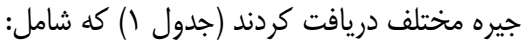

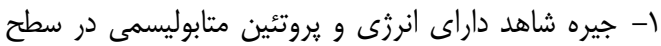

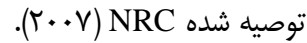

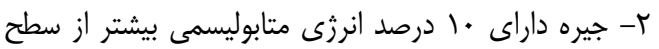

توصيه شده ץ- جيره داراى • إ درصد يروتئين متابوليسمى بيشتر از سطح

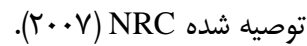
fأ- جيره داراى • أ درصد انرزى و يروتئين متابوليسمى بيشتر

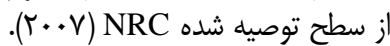

خوراك روزانه به صورت جيده توره كاملاً مخلوط و در دو دو وعده

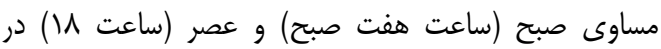



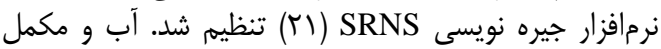

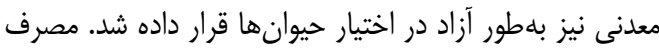

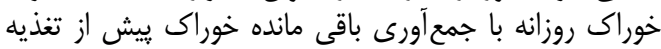

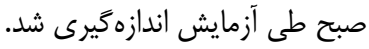

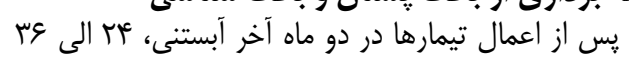

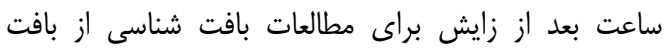

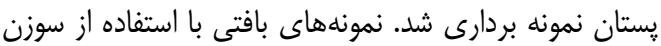









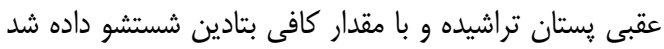

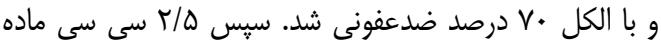

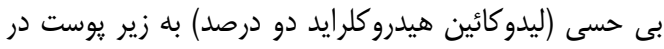

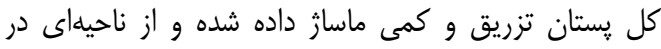

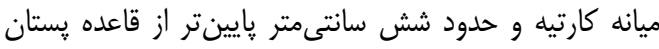

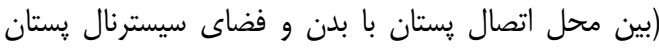



تأثير افزايش سطوح انرثى و يروتئين متابوليسمى در كامه انتهايى آبستى بر رشد و

جدول آ- اجزاى خوراكى (درصد ماده خشك) و تركيب شيميايى (درصد ماده خشك) و محتواى انرزى (مكاكالرى در كيلو گرم) جيرههاى Table 1. Ingredient (\% of dry matter) and chemical composition of experimental diets

آزمايشى آجزى

\begin{tabular}{|c|c|c|c|c|}
\hline \multicolumn{4}{|c|}{ جيرههاى آزمايشى } & \multirow[b]{2}{*}{ اقلام خوراكى } \\
\hline • ا درصد انرزى و يروتئين متابوليسمى & •ا درصد بروتئين متابوليسمى. & •ا درصد انرزى متابوليسمى. & كنترل & \\
\hline $1 N / 11$ & $1 \% / .$. & $N / A \mu$ & $19 / 09$ & دانه جو \\
\hline r & r./9T & $\tau \cdot / \% \Delta$ & r r & دانه ذرت \\
\hline Q/QT & $\mid r / 1$. & $1 / 19$ & V/T\& & تفاله جغندر \\
\hline - &.$/ \cdot \mathrm{Vr}$ & $r / \Delta q$ & $r / \cdot V$ & سبوس كندم \\
\hline 1/91 & $r / .$. & - & $r / \cdot V$ & كنجاله سويا \\
\hline$r .1 . r$ & $r) / .$. & $\mathrm{V} / \mathrm{TV}$ & $r \cdot / \Lambda r^{e}$ & علوفه يونجه \\
\hline$r \Delta / V T^{e}$ & $T V / .$. & rV/Ar & re/9D & كاه كندم \\
\hline 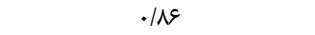 &.$/ 9$ & - /AV & $\cdot / 9$ & مكمل ويتامينه و معدنى \\
\hline $9 / 1$ & $1 . / 8$ & १/. & $9 / 9$ & يروتئين خام \\
\hline$r / T \Delta f$ & T/NGS & $r / T \Delta \Delta$ & T/IFe & 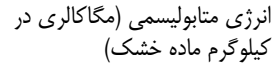 \\
\hline Af & $\Lambda$ & v^ & v & يروتئين متابوليسمى (كرم در روز) \\
\hline $1 \ldots$ & $1 \ldots$ & $1 \ldots$ & $1 .$. & جمع \\
\hline
\end{tabular}

كاهش در روند توسعه غده يستانى و توليد شير بعد از زايش

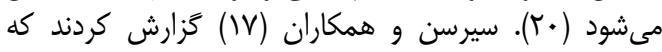



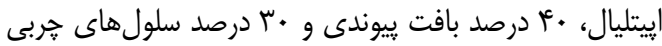

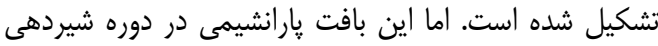



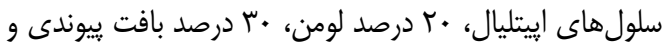



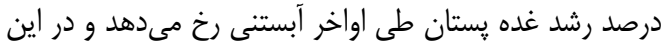

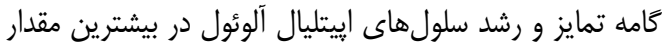

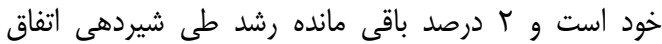

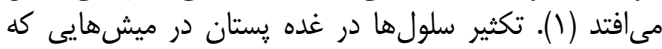

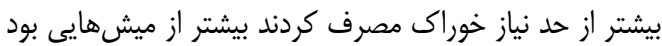



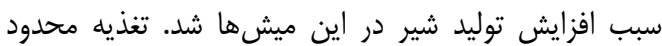

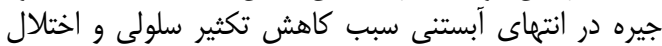

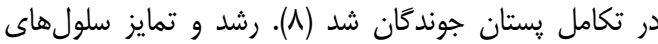

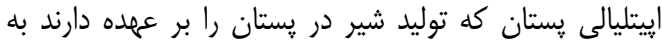



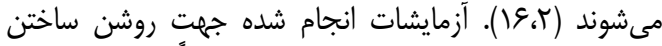


GH-IGF-I

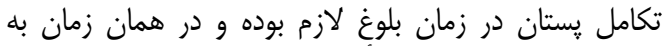

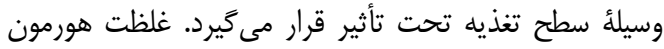





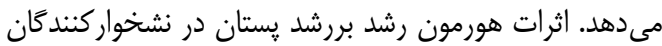

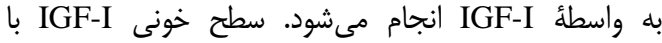

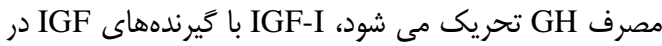

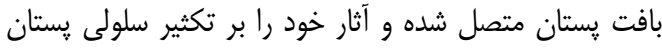





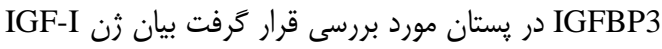

\section{نتايج و بحث}

تعداد آلوئولهاى يستان تحت تأثير جيرههاى آزمايشى جائ

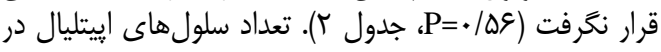

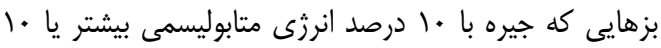

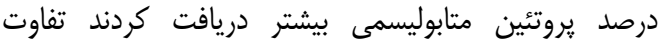





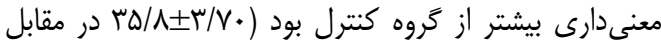
(



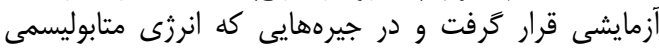

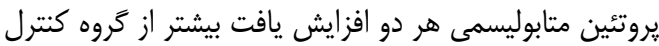



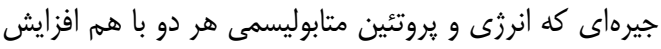

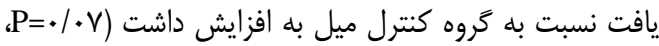



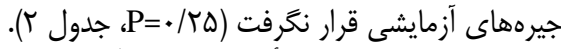

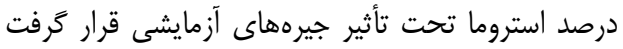





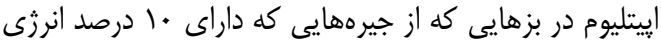

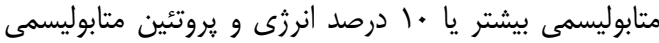



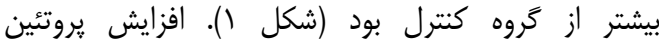

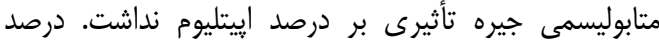

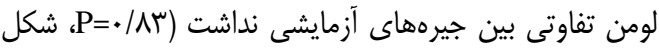

درصد سلولهاى اييتليال و درصد استروما تحت تأثير

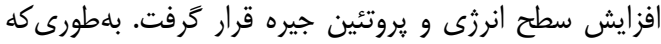

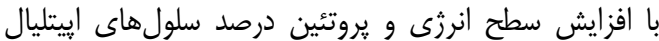

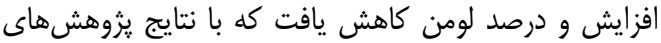

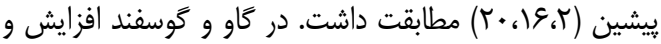
كاهش سطح انرزى جيره از نياز دام در دوره آبستنى سبب دور 
برهها افزايش داد (T). سطح انرزى و يروتئين طى شيردهى

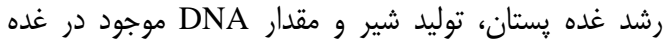

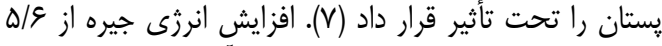

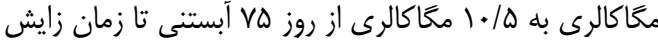



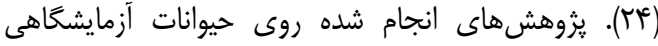

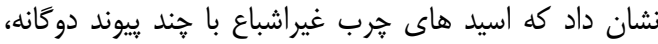





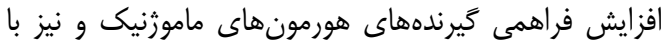

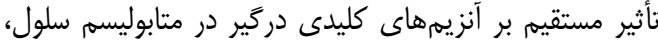

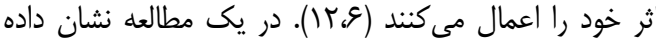

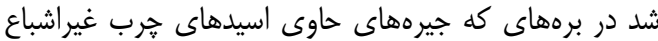

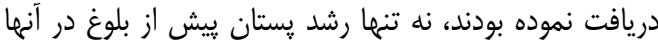



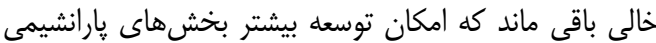







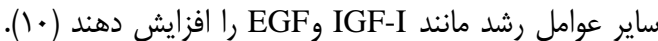

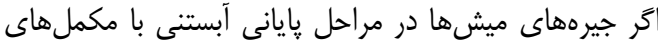

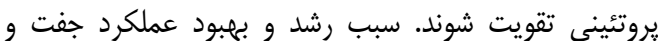

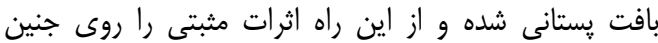





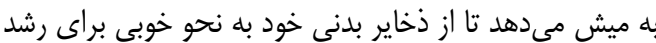

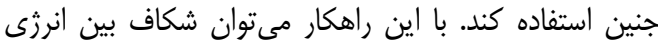










تكامل بستان در زمان زايش نداشت (9).

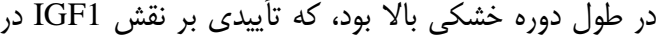

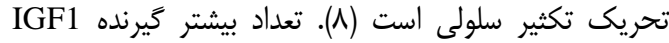

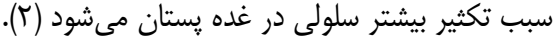

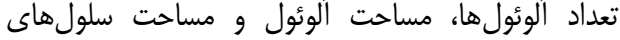

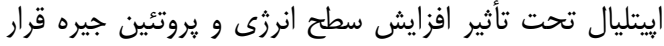



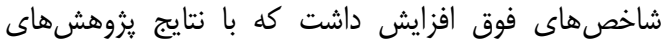

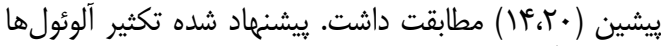

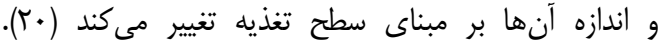

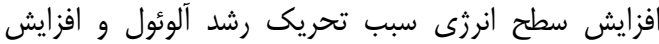

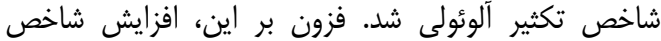

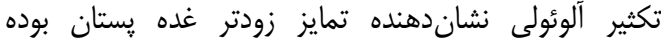

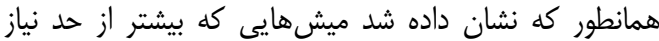



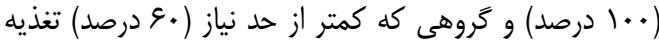



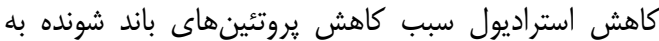

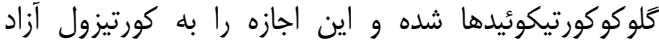

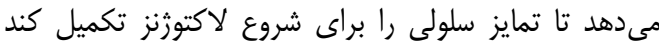

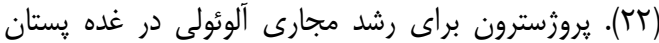

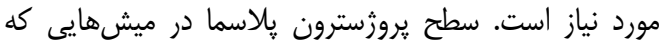

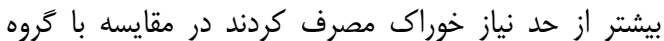



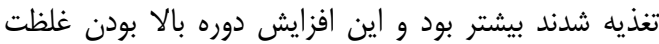

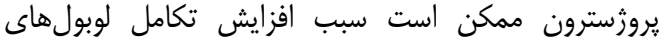

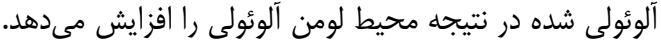

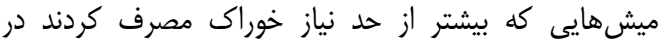

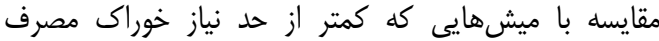

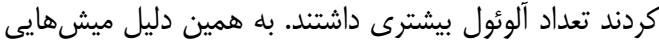



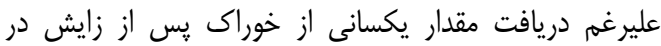

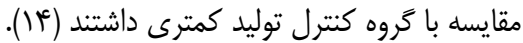

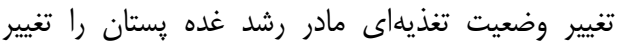
مىدهد (I). براى مثال افزايش انرزى جيره ماموزنز راد در بنان 
$\Delta \wedge$ تأثير افزايش سطوح انرزى و يروتئين متابوليسمى در كامه انتهايى آبستى بر رشد و .


شكل ا- تأثير جيرههاى آزمايشى بر درصد لومن، استروما و إيتليوم بافت يستان بزهاى سيستانى

Figure1. Effect of experimental diets on lumen percentage, stroma percentage and epithelium percentage of mammary tissue of sistani goats

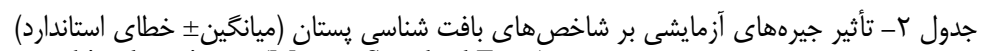
Table 2. Effect of experimental diets on mammary histology items (Means \pm Standard Error)

\begin{tabular}{|c|c|c|c|c|c|}
\hline \multicolumn{5}{|c|}{ جيرههاى آزمايشى } & \multirow[b]{2}{*}{ شاخص } \\
\hline P-Value & • • د درصد انرزى و يروتئين & متابوليسمى بيشتر & •ا درصد انرزى متابوليسمى & 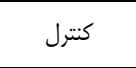 & \\
\hline.$/ D S$ & $r \omega / \Lambda \cdot \pm I / Q T$ & $r T / \Psi \pm T / I V$ & $r \mu / \cdot \pm \cdot / q$ & $T H / \cdot \pm V / \Delta f$ & تعداد آلوئول \\
\hline $.1 \cdot v$ & $r \Delta / \Lambda \pm r / \nu \cdot{ }^{a}$ & $r V / r \pm \cdot / q^{D}$ & $r q / r \pm \cdot / \Delta \gamma^{a b}$ & $r g / F \pm r / G r^{D}$ & تعداد سلولهاى اييتليال \\
\hline.$/ \cdot v$ & $r q . / V v^{2} \pm \varepsilon / V^{a}$ & $r V T / \Psi \pm \Psi / N \varphi^{D}$ & $T Y N / \mathcal{F} \pm r / \uparrow \varepsilon^{a D}$ & $r V \Psi / \mu \pm \Delta / r \cdot{ }^{D}$ & مساحت آلوئول (ميكرومترمربع) \\
\hline r & $\mid r \omega / r \pm \Delta / \kappa v^{a}$ & $\mid r r / r \pm 1 / V g^{a b}$ & $\mid r \Delta / \wedge \pm 1 / q r^{\mathrm{aa}}$ & $\mid r \cdot / \Delta \pm r / q \cdot{ }^{D}$ & مساحت إيتليال (ميكرومترمربع) \\
\hline$\cdot / T \Delta$ & $\mid \omega \Delta / \Delta \pm 1 / \varepsilon \varphi^{\mathrm{a}}$ & $|\mp q / \cdot \pm 1 / 4|^{D}$ & $\mid \omega r / \mathcal{\varepsilon} \pm \Gamma / / \mu^{\mathrm{ab}}$ & $\mid \Delta r / \Lambda \pm r / \cdot 1^{D}$ & مساحت لومن (ميكرومترمربع) \\
\hline
\end{tabular}

mammary tissue

بعبود رشد و تكامل پِتنان شد كه اين امر مىتواند در توليد

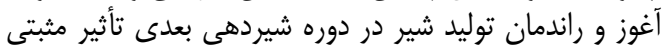
داشته باشد.
1. بلهور كلى نتايج يثوهش حاضر نشان داد افزايش



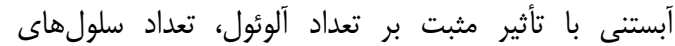

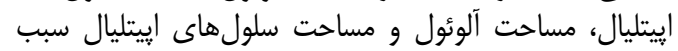


1. Anderson, R.R. 1975. Mammary gland growth in sheep. Journal of Animal Science, 41: 118-123.

2. Blair, H.T., C.M. Jenkinson., S.W. Petereson, P.R. Kenyou, D.S. Van Der Linden, L.C. Devenport, D.D. Mackenzie, S.T. Morris and E.C. Firth. 2010. Dam and granddam feeding during pregnancy in sheep affects milk supply in offspring and reproductive performance in grand-offspring. Journal of Animal Science, 88: 40-50.

3. Capuco, A.V., D.L. Wood, R. Baldwin, K. Mcleod and M.J. Paape. 2001. Mammary cell number, proliferation and apoptosis during a bovine lactation: Relation to milk production and effect of bST. Journal of Dairy Science, 84: 2177-2187.

4. Dawson, L.E.R., A.F. Carson and D.J. Kilpatrick, 1999. The effect of digestible undegradable protein concentration of concentrates and protein source offered to ewes in late pregnancy on colostrum production and lamb performance. Animal Feed Science and Technology, 82: 21-36.

5. Forbes, J.M. 2007. Voluntary food intake and diet selection in farm animals. CAB International, Wallingford, UK. 100-150.

6. Khorasani, G.R., G. de Boer, P.H. Robinson and J.J. Kennelly. 1992. Effect of canola fat on ruminal and total tract digestion, plasma hormones, and metabolites in lactating dairy cows. Journal of Dairy Science, 75: 492-501.

7. Kim, S.W., W.L. Hurley, I.K. Han, H.H. Stein and R.A. Easter. 1999. Effect of nutrient intake on mammary gland growth in lactating sows. Journal of Animal Science, 77: 3304-3315.

8. Knight, C.H. and M. Peaker. 1982 Mammary cell proliferation in mice during pregnancy and lactation in relation to milk yield. Quarterly Journal of Experimental Physiology, 67: 165-177.

9. Kusina, J., J.E. Pettigrew, A.F. Sower, M.R. Hathaway, M.E. White and B.A. Crooker. 1999. Effect of protein intake during gestation on mammary development of primiparous sows. Journal of Animal Science, 77: 925-930.

10. Lin, Y. and Q. Li. 2005. The regulation of development and lactation of mammary gland by leptin. Journal of Animal Science, 1: 63-67.

11. Mahan, D.C. 1990. Mineral nutrition of the sow: a review. Journal of Animal Science, 68: 573-582.

12. McFadden, T.B., T.E. Daniel and R.M. Akers. 1990. Effects of plane of nutrition, growth hormone and unsaturated fat on mammary growth in prepubertal lambs. Journal of Animal Science, 68: 31713179 .

13. Mellor, D.J. and L. Murray. 1985. Effects of maternal nutrition on udder development during the pregnancy and on colostrum production in Scottish Blackface ewes with twin lambs. Research in Veterinary Science, 39: 230-234.

14. Meyer, A.M., J.J. Reed, T.L. Neville, J.F. Thorson, K.R. Maddock-Carlin, J.B. Taylor, L.P. Reynolds, and D.A. Redmer, J.S. Luther, C.J. Hammer, K.A. Vonnahme and J.S. Caton. 2011. Nutritional plane and selenium supply during gestation impact yield and nutrient composition of colostrum and milk in primiparous ewes. Journal of Animal Science, 89: 1627-1639.

15. Prezotto, L.D., L.E. Camacho, C.O. Lemley, F.E. Doscher, J.S. Caton, K.A. Vonnahme and K.C. Swanson. 2013. Effects of nutrient restriction on liver and small intestine energy use in pregnant beef cows. In: Energy and protein metabolism and nutrition in sustainable animal production. Wageningen Academic Publishers, Netherland, 463-464.

16. Safayi, S., P.K. Theil, L. Hou, M. Engbæk, J.V. Nørgaard, K. Sejrsen and M.O. Nielsen. 2010. Continuous lactation effects on mammary remodeling during late gestation and lactation in dairy goats. Journal of Dairy Science, 93: 203-217.

17. Sejrsen, K., J.T. Huber, H.A. Tucker and R.M. Akers. 1982. Influence of nutrition on mammary development in pre- and postpubertal heifers. Journal of Dairy Science, 65: 793-800.

18. Sejrsen, K., S. Purup, M. Vestergaard and J. Foldager. 2000. High body weight gain and reduced bovine mammary growth: physiological basis and implications for milk yield potential. Domestic Animal Endocrinology, 19: 93-104.

19. Sinowatz, F., D. Schams, S. Kolle, A. Plath, D. Lincoln and M.J. Waters. 2000. Cellular localization of $\mathrm{GH}$ receptor in the bovine mammary gland during mammogenesis, lactation and involution. Journal of Endocrinology, 166: 503-510.

20. Swanson, T.J., C.J. Hammer, J.S. Luther, D.B. Carlson, J.B. Taylor, D.A. Redmer, T.L. Neville, J.J. Reed, L.P. Reynolds, J.S. Caton and K.A. Vonnahme. 2008. Effects of gestational plane of nutrition and selenium supplementation on mammary development and colostrum quality in pregnant ewe lambs. Journal of Animal Science, 86: 2415-2423.

21. The Small Ruminant Nutrition System (SRNS). 2007

22. Tucker, H.A. 1987. Quantitative estimates of mammary growth during various physiological states: A review. Journal of Dairy Science, 70: 1958-1966.

23. Vonnahme, K.A., C.M. Weinhold, P.P. Borowicz, T.L. Neville, D.A. Redmer, L.P. Reynolds and J.S. Caton. 2011. Supranutritional selenium increases mammary gland vascularity in postpartum ewe lambs. Journal of Dairy Science, 94: 2850-2858.

24. Weldon, W.C., A.J. Thulin, O.A. MacDougald, L.J. Johnston, E.R. Miller and H.A. Tucker. 1991. Effects of increased dietary energy and protein during late gestation on mammary development in gilts. Journal of Animal Science, 69: 194-200. 


\title{
Effect of Increasing Metabolizable Energy and Protein During Late Pregnancy on Mammary Growth and Development in Sistani Goats
}

\author{
Farhod Shabrandi ${ }^{1}$, Eisa Dirandeh ${ }^{2}$, Zarbakht Ansari Pirsaraei ${ }^{3}$ and \\ Asadollah Teimouri Yansari ${ }^{4}$
}

\footnotetext{
1 and 3- Graduated M.Sc. Student and Associate Professor, Department of Animal Science, Sari Agricultural Sciences and Natural Resources University

2- Assistant Professor, Department of Animal Science, Sari Agricultural Sciences and Natural Resources University (Corresponding author: dirandeh@gmail.com)

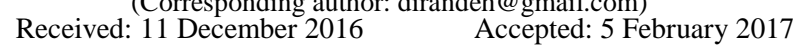

\begin{abstract}
The aim of this study was to consider effect of increasing metabolizable energy and protein during late pregnancy on mammary growth and development in sistani goats. Twenty eight pregnant sistani goats with same average body weight and 2 year old age were selected and randomly assigned to four groups at beginning of late pregnancy period (d 100 of pregnancy): 1- Control group with recommendation level of metabolizable energy and protein according to NRC, 2- group with $10 \%$ greater level of metabolizable energy, 3- group with $10 \%$ greater level of metabolizable protein and 4- group with $10 \%$ greater level of metabolizable energy and protein. After two month feeding, mammary samples were removed by biopsy 24-36 h after parturition to consider mammary histological parameters. Results showed number of epithelial cells were greater in goats fed diets with $10 \%$ greater metabolizable energy and protein both compared to control group $(35.8 \pm 3.70$ vs. 26.4 \pm 2.64$)$, but there was no difference among control groups and groups with $10 \%$ greater metabolizable energy or $10 \%$ greater metabolizable protein alone. Epithelium area $(\mu \mathrm{m})$ affected by diets and were greater in groups with $10 \%$ greater metabolizable energy and protein compared to control groups $(\mathrm{P}=0.03)$. Percentage of stroma affected by diets $(\mathrm{P}=0.001)$ and were decreased by increasing metabolizable energy, metabolizable protein or both compared to control group. Percentage of epithelium affected by diets $(\mathrm{P}=0.008)$ and were greater in groups with greater metabolizable energy and groups with greater metabolizable energy and protein compared to control group. In conclusion increasing $10 \%$ metabolizable energy and protein both during late pregnancy improved mammary growth and development with increasing number and percentage of epithelial cells, increasing alveoli and epithelium area and decreasing percentage of stroma in sistani goats that could have positive effect of cololstrum production and milk yiled in subsequent lactation period.
\end{abstract}

Keywords: Alveoli, Metabolizable energy, Mammary tissue, Epithelial cell, Sistani goat 